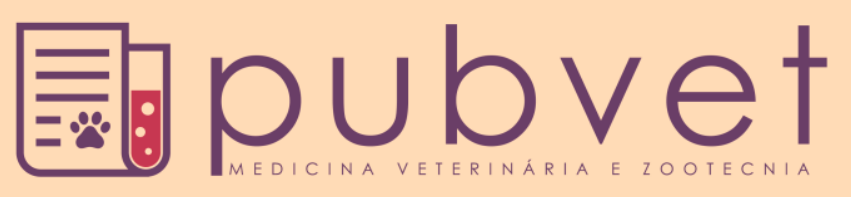

https://doi.org/10.22256/pubvet.v12n4a65.1-12

\title{
Nematoides gastrintestinais na ovinocultura de corte sob regime de pastejo
}

\author{
Francisca Fernanda da Silva Roberto ${ }^{\bullet}$ 1* Gelson dos Santos Difante $^{\ominus 2}$, Lilian Giotto \\ $\operatorname{Zaros}^{\ominus 2}$, Antonio Leandro Chaves Gurgel ${ }^{\ominus} 3$
}

${ }^{I}$ Universidade Federal do Rio Grande do Norte. Mestrado em Produção Animal, Macaíba, RN, Brasil. nandinha_roberto@yahoo.com.br.

${ }^{2}$ Universidade Federal do Rio Grande do Norte, Prof. Zootecnia, Macaíba, RN. Brasil. gdifante@ hotmail.com.

${ }^{3}$ Universidade Federal do Rio Grande do Norte. Mestrado em Produção Animal, Macaíba, RN, Brasil.Antonioleandro09@gmail.com.

*Autor para correspondência

RESUMO. A ovinocultura se faz atuante em praticamente todos os continentes, a ampla difusão da espécie se deve principalmente a seu poder de adaptação. Devido aos fatores geoclimáticos, os países tropicais e subtropicais se destacam e se estabelecem no cenário agropecuário, e o Brasil não se torna exceção nesse mercado. O Brasil por possuir parte considerável do rebanho produzido em pasto, que se constitui em uma das formas econômicas e práticas de produzir e oferecer volumoso aos ruminantes, é um dos principais produtores de carne a um dos menores custos de produção. Os climas tropicais e subtropicais além de favorecer condições ideais para a produção e desenvolvimento dos setores agrícolas e pecuários como, por exemplo, o cultivo de pastagens e a criação de ruminantes, também proporciona condições favoráveis para o desenvolvimento e sobrevivência dos nematoides gastrintestinais, que por sua vez atuam negativamente no desempenho dos animais, em especial, os ovinos. Os nematoides gastrintestinais quando não controlados podem causar prejuízos de 30 a $40 \%$ no desempenho animal, principalmente o comprometendo no desenvolvimento de animais jovens e de matrizes em período reprodutivo que são as categorias mais sensíveis, e que estão intimamente ligados ao crescimento do plantel. Os principais nematoides que acometem os pequenos ruminantes e de maior importância econômica para e exploração de ovinos são: Haemonchus contortus e Trichostrongylus axei, ambos localizados no abomaso; Trichostrongylus colubriformis, Strongyloides papillousus, Cooperia sp. e Bunostomum trigonocephalum, no intestino delgado e Oesophagostomum columbianum, Trichuris ovis, T. globulosa e Skrjabinema sp., no intestino grosso. Características morfofisiológicas das plantas forrageiras como a estrutura foliar, hábito de crescimento e produção de massa verde, associados a fatores climáticos, podem ser fatores que influenciam a permanência dos diferentes estágios de vida livre dos nematoides gastrintestinais no ambiente, pastos que não proporcionam incidência de raios solares no estrato inferior das touceiras e solos, propiciam sombreamento e umidade podendo potencializar a reinfecção dos animais.

Palavras chave: endoparasitos, Haemonchus contortus, ovinos, pasto

\section{Gastrointestinal nematodes in sheep of cutting under grazing regime}

ABSTRACT. Sheep breeding is practiced in practically all the continents, the wide diffusion of the species is due mainly to its power of adaptation. Due to geoclimatic factors, tropical and subtropical countries stand out and settle in the agricultural scenario, and Brazil does not become an exception in this market. Brazil, because it has a considerable part of the herd produced in pasture, which is one of the economic and practical ways of producing and offering bulky ruminants, is one of the main meat producers at one of the lowest production costs. Tropical and subtropical climates, in addition to favoring optimal 
conditions for the production and development of agricultural and livestock sectors, such as pasture and ruminant farming, also provide favorable conditions for the development and survival of gastrointestinal nematodes. Negative performance of the animals, especially the sheep. Gastrointestinal nematodes, when uncontrolled, can cause 30 to $40 \%$ losses in animal performance, especially in the development of young animals and reproductive matrices that are the most sensitive categories, and which are closely related to the growth of the stock. The main nematodes that affect the small ruminants and of greater economic importance for the exploitation of sheep are: Haemonchus contortus and Trichostrongylus axei, both located in the abomasum; Trichostrongylus colubriformis, Strongyloides papillousus, Cooperia sp. and Bunostomum trigonocephalum, in the small intestine and Oesophagostomum columbianum, Trichuris ovis, T. globulosa and Skrjabinema sp., in the large intestine. Morphophysiological characteristics of forage plants such as foliar structure, habit of growth and green mass production, associated to climatic factors, may be factors that influence the permanence of the different stages of free life of the gastrointestinal nematodes in the environment, pastures that do not provide lightning in the lower stratum of the clumps and soils, provide shading and humidity and may potentiate the reinfection of the animals.

Keywords: endoparasites, Haemonchus contortus, sheep, pasture

\section{Nematodos gastrointestinales en la producción de ovinos de carne bajo sistema de pastoreo}

RESUMEN. La producción de ganado ovino se hace actuante en prácticamente todos los continentes, la amplia difusión de la especie se debe principalmente a su poder de adaptación. Debido a los factores geoclimáticos, los países tropicales y subtropicales se destacan y se establecen en el escenario agropecuario, y Brasil no se convierte en excepción en ese mercado. El Brasil por poseer parte considerable del rebaño producido en pasto, que se constituye en una de las formas económicas y prácticas de producir y ofrecer forrajes a los rumiantes, es uno de los principales productores de carne a uno de los menores costos de producción. Los climas tropicales y subtropicales además de favorecer condiciones ideales para la producción y el desarrollo de los sectores agrícolas y ganaderos, como el cultivo de pasturas y la producción de rumiantes, también proporciona condiciones favorables para el desarrollo y la supervivencia de los nematodos gastrointestinales, que por a su vez actúan negativamente en el desempeño de los animales, en especial, los ovinos. Los nematodos gastrointestinales cuando no controlados pueden causar pérdidas de 30 a $40 \%$ en el desempeño animal, principalmente comprometiendo el desarrollo de animales jóvenes y de matrices en período reproductivo que son las categorías más propensa, y que están íntimamente ligados al crecimiento del plantel. Los principales nematodos que afectan a los pequeños rumiantes y de mayor importancia económica para y explotación de ovinos son: Haemonchus contortus y Trichostrongylus axei, ambos localizados en el abomaso; Trichostrongylus colubriformis, Strongyloides papillousus y Cooperia sp. en el intestino delgado y Oesophagostomum columbianum, Trichuris ovis, T. globulosa y Skrjabinema sp., en el intestino grueso. Las características morfofisiológicas de las plantas forrajeras como la estructura foliar, hábito de crecimiento y producción de masa verde, asociadas a factores climáticos, pueden ser factores que influencian la permanencia de las diferentes etapas de vida libre de los nematodos gastrointestinales en el ambiente, pastos que no proporcionan incidencia de rayos solares en el estrato inferior de las macollas y suelos, propician sombreado y humedad pudiendo potenciar la reinfección de los animales.

Palabras clave: endoparásitos, Haemonchus contortus, ovinos, pasto

\section{Introdução}

A produção zootécnica de ovinos é uma atividade executada mundialmente. O Brasil vem ao longo dos anos, se estabelecendo no cenário agropecuário global, e a ovinocultura não se torna exceção nesse mercado (Jimenez-Sanz et al., 
2016). Segundo a FAO (2015), o Brasil ocupa a $18^{\mathrm{a}}$ posição na classificação mundial de produtor de ovinos, contendo um rebanho efetivo com mais de 18 milhões de indivíduos, distribuídos em aproximadamente $436 \mathrm{mil}$ estabelecimentos agropecuários, sendo que a região Nordeste concentra $60,5 \%$ da população ovina (ANUALPEC, 2017).

A utilização das áreas de pastagens vem sendo cada vez mais exploradas como fonte primária de energia na dieta de ruminantes, proporcionando papel importante na pecuária de corte, incrementando a oferta de produtos e consequentemente viabilizando a competitividade do sistema (Euclides Filho, 2004). No entanto, os sistemas de produção que incluem pastejo dos animais é um dos fatores que contribui com o aumento da infecção por nematoides gastrintestinais, devido ao ciclo de vida livre desses parasitos ao ocorrer no microclima das pastagens, em virtude da deposição das fezes do hospedeiro contendo ovos morulados no pasto. Desta forma, a presença das larvas infectantes (L3) na pastagem se torna frequente. Os ovinos são susceptíveis a ação das nematoides gastrintestinais, sendo as infecções causadas por estes o principal fator limitante desse setor pecuário, seguidos de falta de crédito e rural e pastagens cultivadas (Aquino et al., 2016). Esses endoparasitos acometem todas as faixas etárias, causando perdas de peso de 30 a $40 \%$ nos animais jovens, e aproximadamente $60 \%$ dos prejuízos econômicos, tornando a atividade economicamente inviável (Lino et al., 2016).

Nesse contexto, o objetivo dessa revisão é realizar um levantamento bibliográfico sobre os nematoides gastrintestinais na ovinocultura de corte.

\section{Ovinocultura de corte no Brasil}

A espécie ovina foi uma das primeiras a ser domesticada pelo homem. É uma cultura secular que está presente na história da humanidade até os dias atuais. O intuito da criação dessa cultura pelos povos antigos era proporcionar alimento (carne e leite), e proteção pelo uso de peles e lã que servia como abrigo contra as intempéries do ambiente. A Revolução Industrial na Europa e o aumento das indústrias de beneficiamento e o crescimento populacional urbanizado, juntos foram os fatores responsáveis pelo maior poder de compra e consumo de carne. Sendo assim, a demanda pelos produtos cárneos impulsionou a produção, e os ovinos se mostraram uma fonte de carne importante a ser produzida e comercializada ( $\underline{\text { Otto }}$ et al., 1997).

A ovinocultura se faz atuante em praticamente todos os continentes, a ampla difusão da espécie se deve principalmente a seu poder de adaptação. Devido aos fatores geoclimáticos, os países tropicais e subtropicais se destacam e se estabelecem no cenário agropecuário, e o Brasil não se torna exceção nesse mercado (JimenezSanz et al., 2016). No Brasil a cultura foi introduzida durante a colonização pelos portugueses, e vem se estabelecendo por todas as regiões do país, expandindo-se em áreas que até então não possuíam uma atividade pecuária tradicional. Essa expansão aponta um cenário favorável para o agronegócio brasileiro e a contribuição na composição do produto interno bruto (Viana, 2008, Oliveira et al., 2011).

Segundo a FAO (2015), o Brasil ocupa a $18^{\mathrm{a}}$ posição no ranking mundial. $\mathrm{O}$ efetivo de ovinos se apresenta superior a 18 milhões de unidades, com um aumento de 4,5\% entre 2014 e 2015 . Este efetivo é concentrado na Região Nordeste $(60,5 \%)$, seguida pelas Regiões Sul (26,5\%), Centro-Oeste $(5,6 \%)$, Sudeste $(3,8 \%)$ e Norte $(3,6 \%)$ (ANUALPEC, 2017). Sendo que na região Nordeste predominam-se as raças puras e mestiças deslanadas, e com aptidão para o corte e pele, pois, apresentam uma maior rusticidade ao clima tropical.

Com o crescente desenvolvimento das pesquisas e difusão das tecnologias agropecuárias, que visam o aumento da produção, os produtores vêm investindo a cada dia no setor, com o interesse em aumentar consideravelmente os rebanhos. A produção mundial de carne ovina alcançou cerca de 13,7 milhões de toneladas em 2010, devendo, essa produção atingir 23 milhões em 2020, para suprir a demanda alimentar da população. Grande parte desta produção de carne junto com outros produtos oriundos da ovinocultura é exportada, e esta atividade movimenta cerca de US\$ 11 bilhões todos os anos (Viana, 2008). No Brasil, mesmo com um consumo interno baixo de carne ovina, em comparação as demais espécies, apresenta um excesso de demanda, proporcionando, a necessidade de importação desse produto, principalmente do Uruguai. Para uma análise da representatividade do volume de carne ovina importada do Uruguai pelo Brasil, uma vez que supondo que o consumo per capita no Brasil fosse 
de 400 gramas, seria necessária uma produção próxima ao nível de 80 mil toneladas deste produto no Brasil, para atender aos mais de 190 milhões de habitantes (Viana, 2008). Por este motivo a ovinocultura vem sendo fortalecida, para o deslanchar da atividade pecuária desses animais de pequeno porte, onde consomem uma quantidade menor de alimento, sobrevivem bem a longos períodos de estiagens e são precoces e prolíferos. Portanto, esses fatores entre outros despertam o interesse de pecuaristas em iniciar ou permanecer com a produção de ovinos existente, sempre buscando aumentar a produtividade e melhorar os sistemas pecuários, principalmente utilizando tecnologias e inovações (Lino et al., 2016). Devido às exigências do mercado consumidor em que se preza pela criação racional de animais de produção, este setor produtivo experimenta algumas modificações, ainda que lentamente, tais como: melhorias na assistência técnica e manejos, investimentos em infraestrutura da unidade produtiva, nos estabelecimentos, instalações de frigoríficos e matadouros legalizados e que sigam o abate humanitário entre outros. Entretanto, nos sistemas de produção de pequenos ruminantes existem alguns gargalos que devem ser considerados, durante as diferentes fases de vida dos animais. A disponibilidade e a qualidade nutricional dos alimentos fornecidos, a cadeia produtiva, que por muitas vezes não se completa, e o manejo sanitário, mais precisamente os nematoides gastrintestinais, que proporcionam aos animais crescimento e desempenho retardado, perda de peso, redução do consumo da dieta, queda de produção de leite para as crias, baixa fertilidade, anemia, diarreias, entre outros, e em casos de infecções mistas e maciças levam o animal a óbito (Vieira et al., 2011).

\section{Produção de ovinos em pasto}

O Brasil por possuir parte considerável do rebanho produzido em pasto, que se constitui em uma das formas econômicas e práticas de produzir e oferecer volumoso aos ruminantes é um dos principais produtores de carne a um dos menores custos de produção (Dias-Filho \& Ferreira, 2008). De acordo com estimativas do ANUALPEC (2017), a área total de pastagens (naturais e plantadas) no Brasil é de 172,3 milhões de hectares, boa parte dessas áreas estão localizadas na região Nordeste, em decorrência da extensão territorial. Com a implantação das pastagens cultivadas e manejadas, pode-se aumentar a disponibilidade de biomassa, otimização do consumo, de seus nutrientes e as taxas de lotação animal, melhorando o ganho por área. Entretanto, vale ressaltar que, a produtividade da pecuária de corte ainda é considerada baixa (Dias-Filho \& Ferreira, 2008), sendo necessária melhora substancial desse índice produtivo. Nesse sentido, a planta forrageira assume papel importante para a manutenção desses índices.

O Nordeste brasileiro apresenta características de irregularidades nas chuvas e baixas precipitações pluviométricas, ocorrendo baixa disponibilidade forrageira em quantidade e qualidade, manejos sanitários inadequados também são observados, visto que nas épocas de estiagens, os produtores utilizam os sistemas extensivos e extrativistas para manter o rebanho. Esses aspectos proporcionam baixos índices produtivos, sendo um deles a idade elevada para o abate, estes índices contribuem para estagnação do rebanho ao longo dos anos (Pompeu et al., 2009). A ovinocultura no Nordeste brasileiro é uma atividade técnica e economicamente viável, se forem utilizadas tecnologias adequadas à região priorizando, o manejo alimentar e sanitários a baixos custos. Os sistemas de produção em pastagens cultivadas, vem se mostrando uma alternativa viável para o desenvolvimento desta atividade, implicando nos índices zootécnicos almejados, resultando no incremento substancial, na rentabilidade das atividades agropecuárias, favorecendo a permanência e melhoria na qualidade de vida dos agropecuaristas.

Em um trabalho na região Nordeste realizado por (Emerenciano Neto et al., 2017) avaliando a produção de carne ovina em pastagens cultivadas, obtiveram valores para ganho médio diário (g/dia) 133,$7 ; 142,0 ; 82,1$ e 122,4 para as cultivares Marandu, Piatã, Aruana e Massai, respectivamente, no período chuvoso, com taxa de lotação de Unidade Animal (UA) de $30 \mathrm{~kg} / \mathrm{ha}$ de 24,$7 ; 15,0 ; 17,8$ e 26,6 , para as mesmas cultivares testadas no período seco. Já Gurgel et al. (2017) avaliando o desempenho de ovinos em capimmassai na época seca (outubro, novembro, dezembro e janeiro) em resposta ao manejo do período das águas, observaram ganho médio diário variando entre 79,0; 93,1; 44,8 e 159,5 g/dia e taxas de lotação de 8,$7 ; 9,9 ; 10,7$ e 12,3 UA/ha. Dados estes demonstram que é possível implantar o sistema de pastagem cultivada no Nordeste, ambos os trabalhos apresentados anteriormente foram conduzidos em sistema sequeiro, promovendo ganhos na produção de carne ovina. Entretanto, alguns aspectos devem ser 
considerados, tais como, a escolha da forrageira é de suma importância, considerando o potencial genético, que refletirá na quantidade e qualidade, a forma em que a forragem se mantém disponível para a desfolha, adaptação ao ambiente, aos animais, e as taxas de suporte referente a lotação animal, e como a planta se comporta nos períodos de estiagem, além disso, o manejo correto é essencial para a boa produção forrageira, persistência e consumo pelos animais (Euclides et al., 2009, Difante et al., 2010).

\section{Nematoides gastrintestinais}

Os climas tropicais e subtropicais além de favorecer condições ideais para a produção e desenvolvimento dos setores agrícolas e pecuários como, por exemplo, o cultivo de pastagens e a criação de ruminantes, também proporciona condições favoráveis para o desenvolvimento e sobrevivência dos nematoides gastrintestinais, que por sua vez atuam negativamente no desempenho dos animais, em especial, os ovinos (Andrade et al., 2011). O parasitismo é associação entre dois organismos, com caráter obrigatório ou não, onde um dos organismos (parasito) se beneficia do outro retirando meios, como nutrientes, proteção, condições ambientais ótimas que garantam sua sobrevivência e desenvolvimento, prejudicando o hospedeiro (parasitado), reduzindo seu desempenho natural e em casos de alto desequilíbrio entre os organismos, podendo levar os hospedeiros a óbito. Os nematoides gastrintestinais quando não controladas podem causar prejuízos de 30 a $40 \%$ no desempenho animal, principalmente o comprometimento no desenvolvimento de animais jovens e de matrizes em período reprodutivo que são as categorias mais sensíveis, e que estão intimamente ligados ao crescimento do plantel, tornando a atividade economicamente inviável e impraticável aos produtores (Lino et al., 2016).

Os principais nematoides que acometem os pequenos ruminantes e de maior importância econômica para e exploração de ovinos são: Haemonchus contortus e Trichostrongylus axei, ambos localizados no abomaso; Trichostrongylus colubriformis, Strongyloides papillousus, Cooperia sp. e Bunostomum trigonocephalum, no intestino delgado e Oesophagostomum columbianum, Trichuris ovis, T. globulosa e Skrjabinema sp., no intestino grosso. No Nordeste brasileiro os que apresentam maior prevalência e intensidade de infecção são, $H$. contortus, $S$. papillousus, T. colubriformis, O. colubianum (Amarante, 2009, Silva et al., 2017).

Os rebanhos são acometidos pela maioria das vezes por infecções mistas, e o Haemonchus sp. é o gênero de maior prevalência correspondendo a níveis superiores a $80 \%$ nas cargas parasitárias dos pequenos ruminantes, podendo estar presente no rebanho durante todo o ano, sendo responsável pela enfermidade hemoncose (Amarante \& Oliveira, 2007). Este endoparasito é hematófago, tem como órgão de predileção o abomaso, se fixam na mucosa e sugam o sangue, um indivíduo adulto ocasiona uma remoção em torno de 0,05 $\mathrm{mL} /$ sangue $\mathrm{dia}^{-1}$. Devido ao consumo e extravasamento nas lesões, ocasionando anemia, hipoproteinemia, edema submandibular e mortalidade, dependo do grau de infecção. É considerado o nematoide gastrointestinal mais patogênico e de maior intensidade de infecção, devido ao seu hábito hematófago, apresentando elevado potencial biótico (Urquhart, 1996, Andriola et al., 2011). Embora, este nematoide gastrointestinal possa se encontrar presente no sistema durante todo o ano, sua predominância se faz maior nos períodos chuvosos, isso em razão das condições de temperatura acima de $18{ }^{\circ} \mathrm{C}$ e umidade elevada (80\%) que são preconizadas para o desenvolvimento das fazes de vida livre. Sendo assim, nos períodos de estiagem devido à dessecação por incidência dos raios solares a carga parasitária diminui (Pegoraro et al., 2008, Andriola et al., 2011). O segundo gênero em ordem de importância para a ovinocultura é Trichostrongylus $\mathrm{sp}$. ocasionando a enfermidade tricostrongiloidíase. Habitam o duodeno e intestino delgado anterior, penetram abaixo do epitélio do órgão em que se encontram presentes, causando lesões na mucosa intestinal, atrofia das vilosidades, espessamento da mucosa, erosão do epitélio, e exsudação de proteínas séricas para a luz do intestino, comprometendo a digestão e absorção de nutrientes. Em maciças infecções os animais podem apresentar anorexia, diarreia e edema submandibular. Se encontra presente em praticamente em todos os sistemas de produção de pequenos ruminantes (Abrão et al., 2010). Quando comparado com Haemonchus sp. os estágios de vida livre são mais resistentes ao frio e a dessecação, sendo um agravante para o controle ambiental do mesmo. Não é hematófago, porém, está associado a anemia (Pegoraro et al., 2008). Oesophagostomum sp. é um parasito do intestino grosso dos pequenos ruminantes, que ocasiona resposta inflamatória com formação de nódulos 
visíveis a olho nu, os quais são contaminados por bactérias, deixando o intestino impróprio para comercialização e processamento (como material cirúrgico para sutura e pele de linguiça). Alguns sinais clínicos observados são, diarreias intensas e esverdeada, podendo ser sanguinolentas, apatia e anorexia, prostração e morte em animais jovens. Em casos de infecções maciças a debilitação progressiva do animal e sinais sobre produção de carne e lã, podem ser expressados (Abrão et al., 2010). O nematoide gastrintestinal Strongyloides sp. apresenta aspectos biológicos distintos dos demais, pois, as larvas infectantes destes infectam seus hospedeiros por penetração cutânea, ingestão de pastagens contaminadas e pela via galactogênica, que consiste na transmissão da matriz para a cria, pela ingestão de colostro/leite. Essa espécie pode habitar o epitélio do intestino delgado, duodeno e jejuno, levando a reações inflamatórias, semelhante aos já citados anteriormente (Amarante, 2009, Abrão et al., 2010). Em infecções maciças pode ocorrer febre, pneumonia e perturbações bronco pulmonar, esses sinais são em resposta a migração das larvas pelos pulmões, porém, são pouco evidenciadas e desaparecem em poucos dias (Andriola et al., 2011).

\section{Ciclo biológico dos nematoides gastrintestinais}

Grande parte dos nematoides tem seu desenvolvimento semelhante (Figura 1). Inicialmente o hospedeiro elimina suas fezes contendo os ovos morulados no ambiente, os primeiros estádios larvais, que contemplam a larva de primeiro estágio (L1) e larva de segundo estágio (L2), ocorre no interior do bolo fecal no ambiente, e durante essas fases se alimentam de microrganismos e matéria orgânica (Amarante, 2009, Abrão et al., 2010). Em presença de condições edafoclimáticas ideais, as L2 desenvolvem-se para a larva de terceiro estágio (L3), que são denominadas de larvas infectantes, pois, para completar o seu ciclo elas entram em contato com os hospedeiros, ocorrendo a infecção.

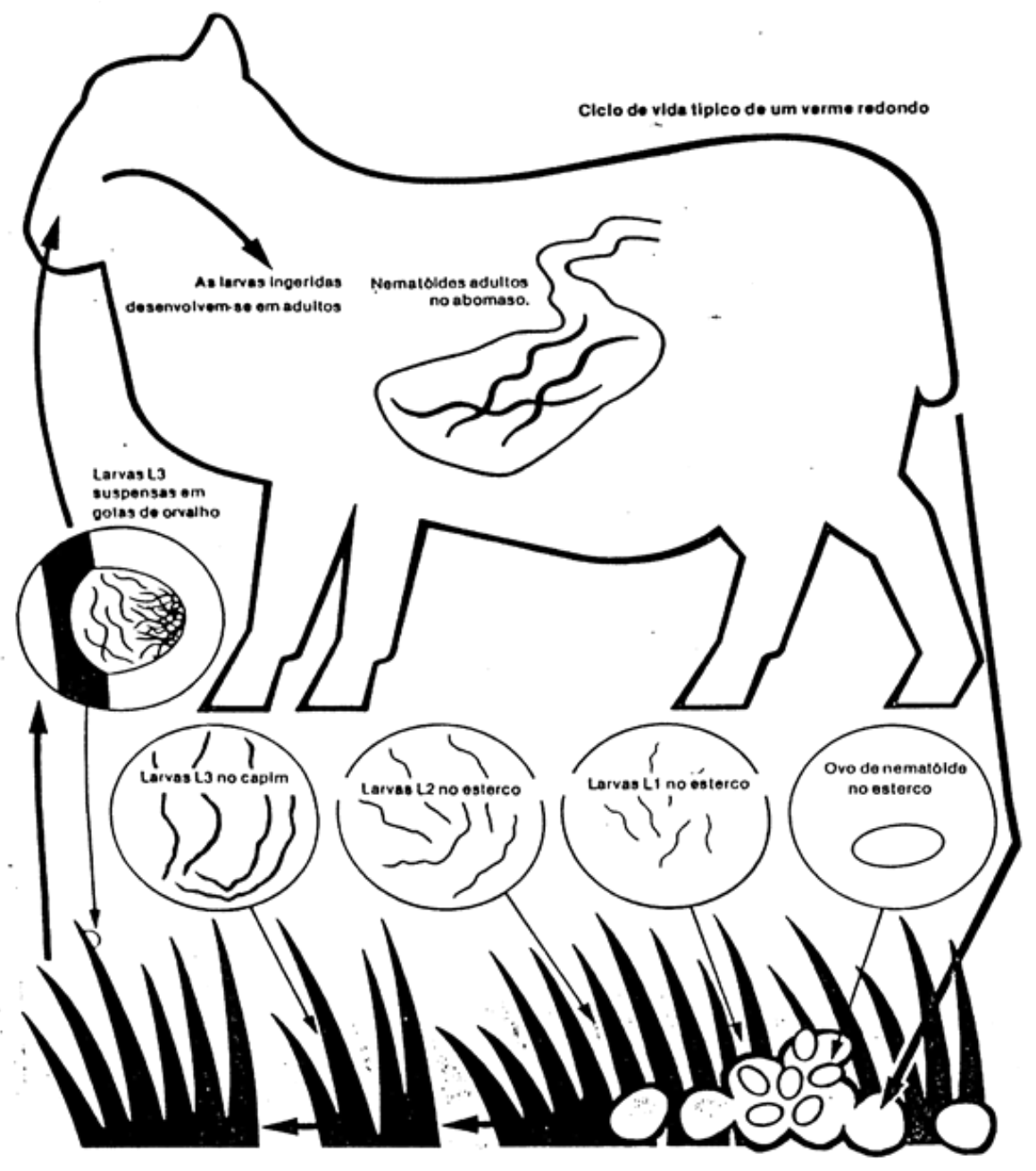

Figura 1. Ciclo de vida de um nematoide. Fonte: Otto et al. (1997). 
Abrão et al. (2010) citam que a L3 é a forma mais ativa e nos períodos em que na pastagem a temperatura, e a irradiação solar são baixas e a umidade é favorável, elas migram do solo e da base das touceiras para a parte superior das forrageiras, com a finalidade de serem ingeridas pelos ovinos durante o processo de desfolha no pastejo, quando as L3 abandonam as fezes e migram para o pasto, essa migração é influenciada pela intensidade e frequência das chuvas, pela temperatura e pela morfologia das forrageiras (Rocha et al., 2007, Amarante, 2009, Lopes et al., $\underline{2016)}$.

Quando ocorre o aumento da temperatura e irradiação solar, elas migram inversamente para se protegerem, mantendo assim sua sobrevivência. Após a ingestão das L3, no trato gastrintestinal, é liberada a bainha retida na fase de L2, que tem por função a proteção contra as intempéries (Urquhart, 1996, Abrão et al., 2010). No interior do hospedeiro a L3 se direciona a seu órgão de predileção, fixa-se e desenvolvem-se para a fase de quarto estágio (L4) e posteriormente para a fase adulta, estando apta a reprodução, dando continuidade ao ciclo (Amarante, 2009, Abrão et al., 2010).

Após a infecção, as larvas podem torna-se metabolicamente inativas por um período que pode durar meses, essa fase é denominada hipobiose, isso ocorre quando o ambiente não apresenta características ideais para o desenvolvimento dos ovos e larvas de primeiros estádios. Quando as condições ambientais voltam a apresentar condições favoráveis a hipobiose é cessada.

Entretanto, nas regiões tropicais, onde os invernos são mais brandos, essa característica não é tão expressiva na epidemiologia da transmissão parasitária (Abrão et al., 2010). Na região semiárida, o período seco aumenta o número de larvas hipobióticas na mucosa gastrintestinal. As larvas hipobióticas representam $23 \%$ e $81 \%$ da população parasitária nos períodos chuvoso e seco do ano, respectivamente (Charles, 1995).

No sistema de produção de ovino a pasto, as condições ambientais e o microclima das pastagens têm grande influência no desenvolvimento e na sobrevivência dos nematoides gastrintestinais nas fases de livre, favorecendo ou não a migração das L3 que habitam aquele ambiente, seja no solo, na base das touceiras e/ou na estrutura da planta forrageira pastejada.

\section{Características morfológicas das plantas forrageiras e sua influência no parasitismo animal}

O entendimento da ecologia e epidemiologia desses nematoides gastrintestinais é parte integrante e indispensável para os mecanismos de controle serem mais eficientes. $\mathrm{O}$ controle da helmintose está intrinsecamente ligada à dinâmica populacional dos nematoides gastrintestinais dentro, e principalmente, fora do hospedeiro visto que a proporção entre o hospedeiro e a pastagem é correspondente a 5\% e 95\% (Bowman, 2004), respectivamente. Como já citado é sabido que a infecção se faz nas pastagens. Alguns autores (Niezen et al., 1998a, Niezen et al., 1998b) relataram que animais em diferentes pastos não apresentam mesmos níveis de carga parasitária, sendo necessária a investigação da influência das mesmas, para a geração de escolhas de forrageiras e manejos sanitários de pastagem adequados (Gazda et al., 2012).

O crescimento das plantas forrageiras decorre na mudança da estrutura do pasto, que é definida como sendo a distribuição e o arranjo da parte aérea das plantas que compõem a comunidade vegetal, e é resultante da dinâmica entre o crescimento e remoção de seus componentes morfológicos da biomassa aérea, seja, por animais ou equipamentos (Laca \& Lemaire, 2000). Para manter a qualidade nutricional, a disponibilidade de massa verde, que atendam a produtividade por área e por animal, algumas estratégias de manejo são empregadas voltadas principalmente as folhas e altura do relvado, interferindo nas características estruturais do pasto.

Existem controvérsias, sobre as alturas de pastejo que proporcionem menos contato hospedeiro-parasito, sendo necessários mais estudos para identificar as alturas ideais que proporcionem reduções parasitárias para cada espécie forrageira. Pegoraro et al. (2008) citam que o manejo de altura da pastagem influencia a carga endoparasitária dos ovinos, pois, as ofertas elevadas de massa verde, onde a planta se encontra em seu crescimento máximo, favorecem a formação de um microclima ideal à sobrevivência e desenvolvimento de helmintos em estágio de vida livre, impedindo a infiltração da irradiação solar e dos ventos, evitando a dessecação dos nematoides em fase de vida livre. Porém, esta condição pode favorecer a ingestão pelo animal, da porção superior do estrato forrageiro em que a contaminação se torna reduzida. A altura de pós 
pastejo, em que o pasto se encontra rebaixado e com uma infiltração maior de irradiação solar se torna benéfico para a redução das taxas de desenvolvimento dos nematoides gastrintestinais.

$\mathrm{O}$ uso de forrageiras de pequeno porte e hábito de crescimento rasteiro, estoloníferas (Cynodon, Digitaria e Paspalum), propiciam microclima adequado para a população parasitária e forçam um pastejo rente ao solo, facilitando a migração larval, e uma maior ingestão de L3. Na migração das L3, estudos evidenciam que por volta dos 15 $\mathrm{cm}$ do relvado, é a faixa que apresenta maior concentração dessas larvas (Figura 2).

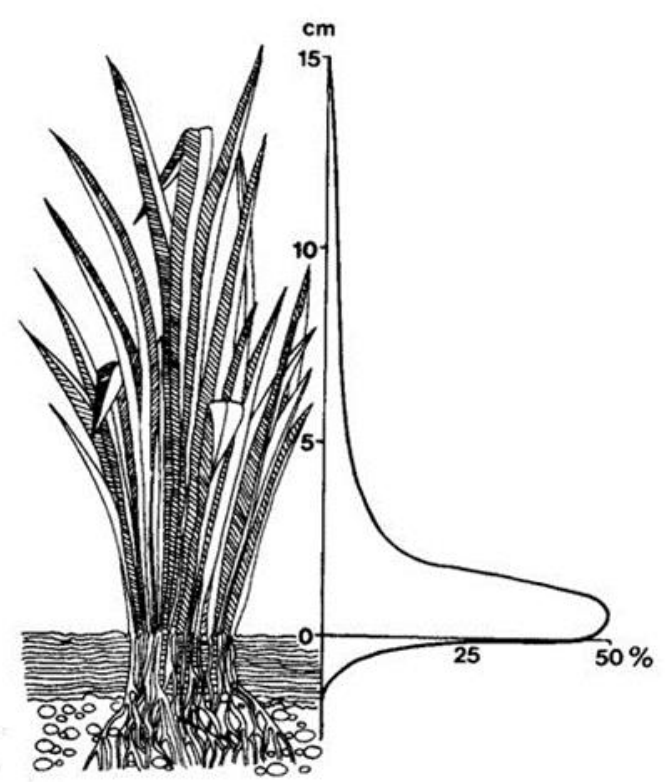

Figura 2. Distribuição vertical de larvas infectantes no perfil da pastagem. Fonte: Vlassof, 1982.

De acordo com Fonseca et al. (2010) forrageiras com o hábito de crescimento cespitoso (Panicum, Brachiária e Andropogon) que possuem crescimento ereto e consequentemente não recobrem bem a superfície do solo, apresentam a vantagem de fornecer maior penetração dos raios solares até a superfície do solo. Manejadas sob pastejo intermitente e com alturas pós pastejo baixa, são boas aliadas para diminuir a contaminação da pastagem. A localização e quantificação das larvas no estrato vegetal, são dados que possibilitam manejos que evite a ingestão de L3 durante a retida de porções vegetais nos bocados, visto que herbívoros em pastejo consomem cerca de 50\% do estrato forrageiro estendido.

A intensidade de pastejo, taxa de lotação, lotação contínua são práticas que devem ser trabalhadas com cautela, pois, essas características podem contribuir para uma contaminação ambiental, reduzindo a seleção de touceiras que apresentam fezes em sua base, aumentando a ingestão de L3 (Pegoraro et al., 2008).

No Nordeste brasileiro a incidência das larvas na pastagem, e consequentemente nos animais ocorre durante os períodos de maiores precipitações pluviométricas. Durante a época de estiagem, que compreendem baixa umidade no solo, maior irradiação solar na pastagem, e menor cobertura de massa verde da forragem, a incidência de L3 decai no ambiente, porém, nos hospedeiros os nematoides gastrintestinais permanecem sobrevivendo (Amarante, 2009).

As características morfológicas das gramíneas forrageiras variam dentre as espécies e com isso podem propiciar um microclima favorável ou desfavorável para a sobrevivência desses helmintos no ambiente. $\mathrm{O} H$. contortus possuem uma considerável adaptabilidade as condições ambientais e no hospedeiro que são desfavoráveis ao desenvolvimento e sobrevivência dos nematoides, como também aos anti-helmíticos, sendo mais dificultoso seu controle (Molento, 2004, Vieira, 2008).

Durante a fase de vida livre existem diferenças no quesito resistência aos intemperes ambientes de acordo com os estádios desses helmintos. Segundo Amarante (2009) o estádio mais resistente é de L3, o de resistência intermediária são os ovos larvados, e mais ovos em fase de desenvolvimento e L1 são os mais susceptíveis. As L3 de H. Contortus e T. Columbrifrmes podem permanecer no ambiente por mais de seis semanas (Amarante, 2009). Cíbalas fecais de ovinos intactas podem compor um reservatório de larvas infectantes, com exceção do período chuvoso e quente do ano, a degradação e liberação das larvas das fezes dos ovinos é muito lenta (Almeida et al., 2005, Rocha et al., 2008, Amarante, 2009).

$\mathrm{O}$ uso de forrageiras de pequeno porte e hábito de crescimento rasteiro, espécies estoloníferas (Cynodon, Digitaria e Paspalum), propiciam microclima adequado para a população parasitária e forçam um pastejo rente ao solo, facilitando a migração larval, e uma maior ingestão de L3. Na migração das L3, estudos evidenciam que por volta dos $15 \mathrm{~cm}$ do relvado, é a faixa que apresenta maior concentração dessas larvas.

De acordo com Fonseca et al. (2010) forrageiras com o hábito de crescimento cespitoso (Panicum, Brachiária e Andropogon), que possuem crescimento ereto e consequentemente 
não recobrem bem a superfície do solo, apresentam a vantagem de fornecer maior penetração dos raios solares até a superfície do solo. Manejadas sob pastejo intermitente e com alturas pós pastejo baixa, são boas aliadas para diminuir a contaminação da pastagem.

A localização e quantificação das larvas no estrato vegetal, são dados que possibilitam manejos que evite a ingestão de L3 durante a retida de porções vegetais nos bocados, visto que herbívoros em pastejo consomem cerca de 50\% do estrato forrageiro estendido.

A intensidade de pastejo, taxa de lotação, lotação contínua são práticas que devem ser trabalhadas com cautela, pois essas características podem contribuir para uma contaminação ambiental, reduzindo a seleção de touceiras que apresentam fezes em sua base, aumentando a ingestão de L3 (Pegoraro et al., 2008).

\section{Larvas infectantes nas pastagens}

No sistema de produção de ovino a pasto, as condições ambientais e o microclima das pastagens têm grande influência no desenvolvimento e na sobrevivência dos endoparasitas na fase de livre, favorecendo ou não a migração das larvas infectantes que habitam aqueles ambientes, seja no solo, na base das touceiras e/ou na estrutura da planta forrageira pastejada.

A incidência das larvas na pastagem, e consequentemente nos animais ocorre durante os períodos de maiores precipitações pluviométricas. Durante a época de estiagem, que compreendem com baixa umidade no solo, maior irradiação solar na pastagem, e menor cobertura de massa verde da forragem, a incidência de larvas infectantes decai no ambiente, porém nos hospedeiros os endoparasitas permanecem sobrevivendo (Amarante, 2009).

As características morfológicas das gramíneas forrageiras variam dentre as espécies, e com isso podem propiciar um microclima mais favorável ou desfavorável para a sobrevivência desses helmintos no ambiente. $\mathrm{O} H$. contortus possuem uma considerável adaptabilidade as condições ambientais e no hospedeiro que são desfavoráveis ao desenvolvimento e sobrevivência dos nematoides, como também aos anti-helmínticos, sendo mais dificultoso seu controle (Molento et al., 2004, Vieira, 2008).

Durante a fase de vida livre existem diferenças no quesito resistência aos intemperes ambientes de acordo com os estádios desses helmintos. Segundo Amarante (2009) citando Levine; Tood junior (1975), o estádio mais resistentes é de larva infectante, o de resistência intermediária são os ovos larvados, e mais ovos em fase de desenvolvimento e larvas de primeiro estádio são os mais susceptíveis. Larvas infectantes de $H$. Contortus e T. Columbrifrmes podem permanecer no ambiente por mais de seis semanas (Amarante, 2009). Cíbalas fecais de ovinos intactas podem compor um reservatório de larvas infectantes, com exceção do período chuvoso e quente do ano, a degradação e liberação das larvas das fezes dos ovinos é muito lenta (Almeida et al., 2005, Rocha et al., 2006, Amarante, 2009).

$\mathrm{Na}$ avaliação de diferentes forrageiras perenes de verão verificou-se que a localização das larvas na pastagem estava numa altura média de $20 \mathrm{~cm}$ do solo e foram encontradas para Tifton 85 (Cynodon sp.) e Paspalum (Paspalum paniculatum) 1,07 e 0,68 larvas/ g MS-1, respectivamente (Dittrich et al., 2004). Em pastagens de Panicum maximum cv. Tanzânia e Mombaça foram encontrados 56 larvas/ kg MS, no estrato de zero a $15 \mathrm{~cm}$ do solo (Chagas et al., 2005, Chagas et al., 2007). Na avaliação do Panicum maximum (Jacq.) cv. Tanzânia-1 foram recuperadas no verão 3001 larvas/ kg MS e no inverno 4505 larvas/ kg MS, localizadas no estrato superior da forragem (Yamamoto et al., 2004).

Almeida et al. (2005) avaliando o desenvolvimento, sobrevivência e distribuição dos estágios pré-parasitários dos nematoides gastrintestinais de bovinos, caprinos e ovinos em pastagem formada por Paspalum notatum (gramabatatais), verificaram que a grande maioria das L3, oriundas de amostras fecais das três espécies de ruminantes, conseguiu atingir a metade superior da gramínea (acima de 12,5 cm). Já Rocha et al. (2007) observaram que no outono, as larvas de $T$. Columbriformis presentes no capim Aruana conseguiram migrar até o dossel e se apresentaram em maior quantidade, entretanto, no capim Braquiária, se encontram mais concentradas na base das touceiras. Durante a primavera, a distribuição das larvas se manteve similar nas forrageiras, avaliadas.

Rocha et al. (2008) recuperaram maior número de larvas L3 de fezes depositadas em forragens altas $(30 \mathrm{~cm})$, pois esta proporcionou um ambiente com condições de sombreamento de umidade favoráveis a permanência e desenvolvimento das 
mesmas, comparadas com as amostras de fezes depositadas em meio às forrageiras de altura inferior $(5 \mathrm{~cm})$.

Em pastagens de inverno formadas por Avena strigosa (aveia preta) e Lolium multiflorum (azevém), Gazda et al. (2012) recuperam no estrato superior 16,01 larvas/g MS e 71,17 larvas/g MS, respectivamente. Mota et al. (2015) avaliando a recuperação de larvas infectantes em pasto composto por Braquiaria brizantha cv. Marandu manejados em duas alturas distintas de 10 e $30 \mathrm{~cm}$, observaram que até 28 dias após a contaminação ainda era possível realizar a recuperação dessas larvas. Concluindo que a partir do $28^{\circ}$ dia a contaminação no pasto com L3 decresça, sendo importante respeitar esse período de descanso.

\section{Conclusões}

No cenário do agronegócio a ovinocultura vem tomando espaço e se estabilizando, porém, ainda encontra entraves para o deslanchar pleno da atividade, sendo um desses a endoparasitose gastrintestinal. $\mathrm{O}$ entendimento da ecologia e epidemiologia desses nematoides gastrintestinais é parte integrante e indispensável para os mecanismos de controle serem mais eficientes. Se faz necessário o acompanhamento parasitológico do rebanho para reduzir os prejuízos produtivos e econômicos.

Além, do desempenho animal, a avaliação da influência das pastagens na carga endoparasitária dos animais, principalmente de pequenos ruminantes, se torna notória visto que estudos comprovam que a planta forrageira pode contribuir ou não com a infecção parasitária, ocasionando grandes prejuízos econômicos ao setor pecuário e consequentemente ao país como um todo.

Sendo assim, a descoberta de plantas forrageiras que contribua com o desempenho animal almejado e com a redução dos níveis de infecção parasitária são de extrema importância para os pesquisadores e pecuaristas.

\section{Referências Bibliográficas}

Abrão, D. C., Abrão, S., Viana, C. H. C. \& Valle, C. R. 2010. Utilização do método Famacha no diagnóstico clínico individual de haemoncose em ovinos no Sudoeste do Estado de Minas Gerais. Revista Brasileira de Parasitologia Veterinária, 19, 70-72.
Almeida, L. R., Castro, A. A., Silva, F. J. \& Fonseca, A. H. 2005. Desenvolvimento, sobrevivência e distribuição de larvas infectantes de nematóides gastrintestinais de ruminantes, na estação seca da baixada fluminense, RJ. Revista Brasileira de Parasitologia Veterinária, 14, 89-94.

Amarante, A. F. T. 2009. Nematoides gastrintestinais em ovinos. Doenças parasitárias de caprinos e ovinos: epidemiologia e controle. . Brasília: Embrapa Informação Tecnológica, Brasília.

Amarante, A. F. T. \& Oliveira, S. R. 2007. Controle de endoparasitoses dos ovinos: uma revisão. Revista Brasileira de Higiene e Sanidade Animal, 1, 14-36.

Andrade, G. M., Moura, M. S. \& Barbosa, F. C. 2011. Eficácia do produto homeopático Verm 100â no controle da verminose ovina: resultados parciais. PUBVET, 5, 1043-1049.

Andriola, L. C., Brito Oliveira, S. V. F., Pereira, J. S., Coelho, W. A. C. \& Ahid, S. M. M. 2011. Diagnóstico de Principais Helmintos em Caprinos no Município de Grossos-RN. Revista Científica de Produção Animal, 13, 141-144.

ANUALPEC. 2017. Anuário da Pecuária Brasileira, 20th edn. Instituto FNP, São Paulo, SP, Brasil.

Aquino, R. S., Lemos, C. G., Alencar, C. A., Silva, E. G., Silva, L. R., Gomes, J. A. F. \& Silva, A. F. 2016. A realidade da caprinocultura e ovinocultura no semiárido brasileiro: um retrato do sertão do Araripe, Pernambuco. PUBVET, 10, 271-281.

Bowman, D. 2004. Parasitologia veterinária de Georgis. Elsevier Brasil.

Chagas, A. C. S., Carvalho, C. O. \& Molento, M. B. 2007. Método famacha: um recurso para o controle da verminose em ovinos. Embrapa Pecuária Sudeste-Circular Técnica, 1, 1-52.

Chagas, A. C. S., Vieira, L. S., Cavalcante, A. C. R. \& Martins, L. A. 2005. Controle de verminose em pequenos ruminantes adaptado para a Região da Zona da Mata/MG e Região Serrana do Rio de Janeiro. Embrapa Caprinos. Circular Técnica. Brasília.

Charles, T. P. 1995. Disponibilidade de larvas infectantes de nematódeos gastrintestinais parasitas de ovinos deslanados no semi-árido pernambucano. Ciência Rural, 25, 437-442.

Dias-Filho, M. B. \& Ferreira, J. N. 2008. 
Barreiras à adoção de sistemas silvipastoris no Brasil. Embrapa Amazônia Oriental, Brasília.

Difante, G., Euclides, V. P. B., Nascimento Júnior, D., Silva, S., Barbosa, R. A. \& Torres Júnior, R. 2010. Desempenho e conversão alimentar de novilhos de corte em capim tanzânia submetido a duas intensidades de pastejo sob lotação rotativa. Revista Brasileira de Zootecnia, 39, 33-41.

Dittrich, J. R., Gazda, T. L., Piazzetta, R. G., Rodrigues, C. S., Oikawa, M. G. \& Soccol, V. T. 2004. Localizacão de larvas L3 de helmintos gastrointestinais de ovinos nas plantas forrageiras: efeito da altura e da espécie vegetal. Archives of Veterinary Science, 9, 4348.

Emerenciano Neto, J. V., Santos, D. G., Lana, A. M. Q., Campos, N. R. F., Lima, V. E. L. \& Moraes, J. D. 2017. Sward structure and herbage accumulation of massai guineagrass pastures managed according to pre-grazing heights, in the northeast of Brazil. Journal of Agricultural Science, 9, 155-193.

Euclides Filho, K. 2004. Supply chain approach to sustainable beef production from a Brazilian perspective. Livestock Production Science, 90, 53-61.

Euclides, V. P. B., Macedo, M. C. M., Valle, C. B., Santos Difante, G., Barbosa, R. A. \& Cacere, E. R. 2009. Valor nutritivo da forragem e produção animal em pastagens de Brachiaria brizantha. Pesquisa Agropecuária Brasileira, 44, 98-106.

FAO. 2015. Statistical Yearbook. Food and Agriculture Organization of the United Nations, Rome, Italy.

Fonseca, D. M., Santos, M. E. R. \& Martuscello, J. A. 2010. Importância das forrageiras no sistema de produção. Universidade Federal de Viçosa, Viçosa, Minas Gerais.

Gazda, T. L., Piazzetta, R. G., Dittrich, J. R., Monteiro, A. L. G. \& Soccol, V. T. 2012. Distribuição de larvas de nematódeos gastrintestinais de ovinos em pastagens de inverno. Ciência Animal Brasileira, 13, 85-92.

Gurgel, A. L. C., Difante, G. S., Emerenciano Neto, J. V., Souza, J. S., Veras, E. L. L., Costa, A. B. G., Netto, R. T. C., Fernandes, L. S., Cunha, J. C. \& Roberto, F. F. S. 2017. Estrutura do pasto e desempenho de ovinos em capim-massai na época seca em resposta ao manejo do período das águas. Boletim de
Indústria Animal, 74, 86-95.

Jimenez-Sanz, A. L., Quirino, C. R., Pacheco, A., Costa, R. L. D., Beltrame, R. T., Rua, M. A. S., Silva, R. M. C. \& Fátima, M.-O. A. 2016. Relação entre fatores associados às parasitoses gastrointestinais, desempenho e estado fisiológico de ovelhas Santa Inês. Agropecuária Técnica, 37, 88-95.

Laca, E. A. \& Lemaire, G. 2000. Measuring sward structure. In: Jones, R. M. (ed.) Field and laboratory methods for grassland and animal production research. Cabi, Wallingford.

Lino, D. M., Pinheiro, R. S. B. \& Ortunho, V. V. 2016. Benefícios do bem-estar animal na produtividade e na sanidade de ovinos. Periódico Eletrônico Fórum Ambiental da Alta Paulista, 12, 124-132.

Lopes, B., Ribeiro, A., Correia, L., Camilo, D. J. \& Cesco, G. 2016. Levantamento de parasitas gastrointestinais em ovinos sob lotação continua. Synergismus Scyentifica UTFPR, 11, 43-46.

Molento, M. B. 2004. Resistência de helmintos em ovinos e caprinos. Revista Brasileira de Parasitologia, 13, 82-86.

Molento, M. B., Tasca, C., Gallo, A., Ferreira, M., Bononi, R. \& Stecca, E. 2004. Método Famacha como parâmetro clínico individual de infecção por Haemonchus contortus em pequenos ruminantes. Ciência Rural, 34, 11391145.

Mota, R. F. M., Urzedo, M. C. C., Macedo, S. A. S., Menezes, R. P., Santos, M. E. R. \& Rosalinski-Moraes, F. 2015. Longevidade de larvas infectantes de tricostrongilídeos (Nematoda: Trichostrongyloidea) em duas alturas de pasto de Brachiaria brizantha cv. Marandu, durante o período das águas, no Triângulo Mineiro. Ars Veterinaria, 31, 68.

Niezen, J. H., Charleston, W. A. G., Hodgson, J., Miller, C. M., Waghorn, T. S. \& Robertson, H. A. 1998a. Effect of plant species on the larvae of gastrointestinal nematodes which parasitise sheep. International Journal for Parasitology, 28, 791-803.

Niezen, J. H., Waghorn, G. C. \& Charleston, W. A. G. 1998b. Establishment and fecundity of Ostertagia circumcincta and Trichostrongylus colubriformis in lambs fed lotus (Lotus pedunculatus) or perennial ryegrass (Lolium perenne). Veterinary Parasitology, 78, 13-21.

Oliveira, M. V., Moura, M. S. \& Barbosa, F. C. 
2011. Avaliação comparativa do método Famacha ${ }^{\circledR}$, volume globular e OPG em ovinos. PUBVET, 5, 1034-1041.

Otto, C., Sá, J. L., Woehl, A. H., Castro, J. A., Reifur, L. \& Valentini, V. M. 1997. Estudo econômico da terminação de cordeiros à pasto e em confinamento. Revista do Setor de Ciências Agrárias, 16, 223-227.

Pegoraro, E. J., Poli, C. H. E. C., Carvalho, P. C. d. F., Gomes, M. J. T. d. M. \& Fischer, V. 2008. Manejo da pastagem de azevém, contaminação larval no pasto e infecção parasitária em ovinos. Pesquisa Agropecuaria Brasileira, 43, 1397-1403.

Pompeu, R. C. F. F., Cândido, M. J. D., Neiva, J. N. M., Rogério, M. C. P., Cavalcante, M. A. B. \& Silva, R. G. 2009. Desempenho de ovinos em capim-tanzânia sob lotação rotativa com quatro proporções de suplementação concentrada Performance of sheep raised on Tanzania grass under intermittent stocking with four proportions of concentrate supplementation. Arquivo Brasileiro de Medicina Veterinária e Zootecnia, 61, 11041111.

Rocha, G. P., Evangelista, A. R., Lima, J. A. \& Rosa, B. 2006. Adubação nitrogenada em gramíneas do gênero Cynodon. Ciência Animal Brasileira, 3, 1-9.

Rocha, R. A., Bricarello, P. A., Rocha, G. P. \& Amarante, A. F. T. 2007. Recuperação de larvas de Trichostrongylus colubriformis em diferentes estratos de Brachiaria decumbens e Panicum maximum. Revista Brasileira de Parasitologia Veterinária, 16, 77-82.

Rocha, R. A., Rocha, G. P., Bricarello, P. A. \& Amarante, A. F. T. 2008. Recuperação de larvas infectantes de Trichostrongylus colubriformis em três espécies de gramíneas contaminadas no verão. Revista Brasileira de
Parasitologia Veterinária, 17, 227-234.

Silva, D. G., Menezes, B. M., Bettencourt, A. F., Frantz, A. C., Corrêa, M. R., Ruszkowski, G., Martins, A. A., Brum, L. P. \& Hirschmann, L. C. 2017. Método FAMACHA® como ferramenta para verificar a infestação parasitária ocasionada por Haemonchus spp. em ovinos. PUBVET, 11, 1015-1021.

Urquhart, G. M. 1996. Parasitologia veterinária, 2 edn. Guanabara Koogan, Rio de Janeiro.

Vlassof, A. 1982. Biology and population dynamics of free living stages of gastrointestinal nematodes of sheep. In: Ross, A. D. (Ed.). Control of internal parasites in sheep. Lincoln College, NZ. p.11-20.

Viana, J. G. A. 2008. Panorama geral da ovinocultura no mundo e no Brasil. Revista Ovinos, 4, 1-9.

Vieira, L. S. 2008. Métodos alternativos de controle de nematóides gastrintestinais em caprinos e ovinos. Embrapa Caprinos $e$ Ovinos, 2, 49-56.

Vieira, L. S., Cavalvante, A. C. R. \& Zaros, L. G. 2011. Manejo sanitário de doenças parasitárias. Embrapa Caprinos e Ovinos, 15, 355-383.

Yamamoto, S. M., Macedo, F. A. F., Grande, P. A., Martins, E. N., Zundt, M., Mexia, A. A. \& Nieto, L. M. 2004. Produção e contaminação por helmintos parasitos de ovinos, em forrageiras de diferentes hábitos de crescimento. Acta Scientiarum. Animal Sciences, 26, 379-384.

Article History:

Received 3 January 2018

Accepted 17 February 2018

Available online 6 April 2018

License information: This is an open-access article distributed under the terms of the Creative Commons Attribution License 4.0, which permits unrestricted use, distribution, and reproduction in any medium, provided the original work is properly cited. 